\title{
УДК 368:519(075.8)
}

\section{ONE PROBLEM OF AN OPTIMAL REINSURANCE CONTRACT DEFINITION \\ ОДНА ЗАДАЧА ЗНАХОДЖЕННЯ ОПТИМАЛЬНОГО ДОГОВОРУ ПЕРЕСТРАХУВАННЯ}

Chornyy R.O. / Чорний P.O. aspr. / acnp.

ORCID: +38(093)-128-95-19

Bevziuk O.V. / Бевзюк O.B. stud. / cmyd.

ORCID: $+38(093)-060-41-15$

Kinash O.M. / Кінаш О.М.

PhD, docent/ канд.фіз.-мат.н., дои. ORCID:+38(050)-430-07-13

Львівський нащіональний університет імені Івана Франка, Львів,

Вул. Університетська 1, 79000 Ivan Franko National University of Lviv,Lviv, 1,Universytetska St., 79000

Анотація. Розглянуто взаємовідносини між страховими компаніями - страховиком та перестрахувальниками. Розглянуто випадок лише двох страхових компаній, які приймають участь у договорі по перестрахування. Знайдено оптимальний договір перестрахування, який б задовольнив иі страхові компанї $i$ досліджено умови його існування, виходячи з критерію очікуваної корисності ризикових ситуачій страхових компаній. 3 а допомогою отриманого результату можна оцінити корисність перестрахування та використати їх для знаходження оптимального виду страхування.

Ключові слова: ризикова ситуачія, оптимальність за Парето, розв `зок Неша.

Ветуп.

Одним 3 найбільш широко використовуваних інструментів забезпечення фінансової стабільності страхової компанії $є$ перестрахування - спеціальний механізм перерозподілу ризику між страховиком і спеціальної структурною одиницею на ринку страхування, що називається перестраховиком(reinsurer).

Економіко-фінансова сфера та життєдіяльність людини пов'язані 3 наявністю різноманітних ризиків. Поняття ризику пов'язане 3 невизначеністю можливої загрози втрат, що випливає зі специфіки різних явищ природи, соціального, політичного й економічного життя суспільства, видів людської діяльності.

Виникає проблема джерела відшкодування втрат. Один з варіантів полягає у покритті збитків за рахунок фінансових ресурсів, що знаходяться в обігу у даного суб'єкта. Другий варіант полягає у створенні спеціальних цільових фондів, призначених для відшкодування збитків - резервних страхових фондів. Третій варіант - це самострахування, коли кожна юридична і фізична особа формує власний резервний фонд. Самострахування $\epsilon$ дорогою й нераціональною формою, що передбачає зменшення фінансових можливостей суб'єктів. 


\section{1. Попередні зауваження. Означення. Твердження.}

Ризикову ситуацію страхової компанії будемо характеризувати парою $(S, F(x))$, де $S$ - капітал компанії перед початком страхових виплат, без урахування початкового капіталу, а $F(x)$ випадкова величина загальних виплат, породжених портфелем страхової компанії.

Означення 1. Корисність ризикової ситуації $(S, F(x))$ з випадковою величиною доходу $Y$ і функцією розподілу $G(y)$ характеризується величиною

$$
U(Y)=\int_{-\infty}^{+\infty} u(y) d G(y)=E u(Y),
$$

де $u(y)$ - функція корисності грошей компанії [3].

В результаті отримуємо, що корисність доходу $Y$ те саме, що корисність ризикової ситуації $(S, F)$ :

$$
U(S, F)=\int_{S-N}^{S} u(y) d G(y) .
$$

Будемо вважати заданими характеристики вигляду [1].

$$
U_{i}\left(S_{i}, F_{i}\right)=\int_{0}^{+\infty} u_{i}\left(S_{i}-x\right) d F_{i}(x)=\int_{0}^{N_{i}} u_{i}\left(S_{i}-x\right) d F_{i}(x) .
$$

Означення 2. Ризикова ситуація $\left(S^{\prime}, F^{\prime}\right) \in$ кращою за ризикову ситуацію $(S, F)$ для $i-$ ї страхової компанії тоді і лише тоді, коли

$$
U_{i}\left(S^{\prime}, F^{\prime}\right)>U_{i}(S, F) .
$$

Перестрахування - це договір між двома страховими компаніями (страховиком i перестраховиком), за яким перестраховик бере на себе відшкодування частини збитків страховика за певну платню. Частіше за все платня вимірюється у відсотках від страхового тарифу і називається тарифом перестрахування. Позначимо тариф перестрахування через $\theta, 0 \leq \theta \leq 1$.

До укладання договору перестрахування страхові компанії мають дохід $S_{1}$ та $S_{2}$, відповідно, з випадковими величинами збитків $X_{1}$ та $X_{2}$.

В загальному випадку $\theta$ - це борелівська функція від випадкових величин збитків $X_{1}$ та $X_{2}$.

$$
\theta\left(X_{1}, X_{2}\right): \Omega \times \Omega \rightarrow \boldsymbol{R}
$$

Нехай борелівська функція $y\left(X_{1}, X_{2}\right): \Omega \times \Omega \rightarrow \boldsymbol{R}$ відповідає за величину страхових виплат, яку сплачує перша страхова компанія після укладення договору. Функція $y\left(X_{1}, X_{2}\right)$ відображає вклад першої страхової компанії при перерозподілі ризику, а $\theta\left(X_{1}, X_{2}\right)$ - долю виплат перестраховику за послугу перестрахування.

Отже, задача знаходження оптимального договору перестрахування така: знайти оптимальну, в термінах функцій корисності $(1.1)$, пару $(\theta, y)$ з множини всіх можливих договорів $M$ :

$$
M=\left\{\left(\theta\left(X_{1}, X_{2}\right), y\left(X_{1}, X_{2}\right)\right) \mid 0 \leq \theta \leq 1, y \leq X_{1}\right\},
$$

яка задовольняє обидві страхові компанії.

Позначимо через $U_{i}(0) \equiv U_{i}\left(S_{i}, F_{i}\right)$ очікувану корисність початкових ризикових ситуацій компаній, які вони мали до укладення договору. Оскільки договір між ними повністю описується парою $(\theta, y)$, то очікувані корисності 
ризикових ситуацій страхових компаній після укладення договору приймають вигляд.

$$
\begin{gathered}
U_{1}(\theta, y)=\int_{0}^{N_{2}} \int_{0}^{N_{1}} u_{1}\left(S_{1} \cdot(1-\theta)-y\right) F_{1}{ }^{\prime}\left(x_{1}\right) F_{2}{ }^{\prime}\left(x_{2}\right) d x_{1} d x_{2} \\
U_{2}(\theta, y)=\int_{0}^{N_{2}} \int_{0}^{N_{1}} u_{2}\left(S_{2}+S_{1} \cdot \theta-x_{1}-x_{2}+y\right) F_{1}{ }^{\prime}\left(x_{1}\right) F_{2}{ }^{\prime}\left(x_{2}\right) d x_{1} d x_{2}
\end{gathered}
$$

Означення 3. Недомінований договір перестрахування, або такий договір, що задається парою $\left(\theta^{*}, y^{*}\right)$, для якої не існує іншої пари $(\theta, y)$, яка б домінувала над нею, називається договором (парою) оптимальним за Парето.

\section{Теорема 1.1}

Пара $\left(\theta^{*}, y^{*}\right) \epsilon$ оптимальною за Парето тоді і тільки тоді, коли існує таке $k>0$, що для всіх договорів $(\theta, y)$ з $M$ виконується нерівність

$$
U_{1}\left(\theta^{*}, y^{*}\right)+k \cdot U_{2}\left(\theta^{*}, y^{*}\right) \geq U_{1}(\theta, y)+k \cdot U_{2}(\theta, y)
$$

Умова (1.5) є еквівалентна умові, що пара $\left(\theta^{*}, y^{*}\right) \epsilon$ розв'язком, який максимізує функціонал [1].

Також $k$ задовольняє систему:

$$
\left\{\begin{array}{l}
\frac{\partial}{\partial y} u_{1}\left(S_{1} \cdot(1-\theta)-y\right)=k \cdot \frac{\partial}{\partial y} u_{2}\left(S_{2}+S_{1} \cdot \theta-x_{1}-x_{2}+y\right) \\
\frac{\partial}{\partial \theta} u_{1}\left(S_{1} \cdot(1-\theta)-y\right)=k \cdot \frac{\partial}{\partial \theta} u_{2}\left(S_{2}+S_{1} \cdot \theta-x_{1}-x_{2}+y\right)
\end{array}\right.
$$

Означення 4. Пара $\left(\theta^{*}\left(X_{1}, X_{2}\right), y^{*}\left(X_{1}, X_{2}\right)\right) \in$ оптимальною, якщо вона задовольняє умови:

$\checkmark$ Пара $\left(\theta^{*}, y^{*}\right)$ оптимальна за Парето;

$\checkmark$ виконуються нерівності

$$
\left\{\begin{array}{l}
U_{1}(0) \leq U_{1}\left(\theta^{*}, y^{*}\right) \\
U_{2}(0) \leq U_{2}\left(\theta^{*}, y^{*}\right)
\end{array}\right.
$$

В нашій роботі ми будемо використовувати так званий розв'язок по Нешу [2], який є найбільш популярний в класичній теорії ігор. Він зводиться до максимізації добутку:

$$
\left(U_{1}(\theta, y)-U_{1}(0)\right) \cdot\left(U_{2}(\theta, y)-U_{2}(0)\right) \rightarrow \max
$$

3 одного з рівнянь системи (1.6) ми отримаємо, що

$$
S_{1} \cdot \theta+y=h\left(k, X_{1}+X_{2}\right),
$$

де $h$ - відома функція двох параметрів.

3 (1.8) функція $h$ несе зміст величини загальних збитків страховика після укладення договору перестрахування.

В цьому випадку корисності ризикових ситуацій компаній:

$$
\begin{aligned}
& U_{1}(\theta, y)=U_{1}{ }^{*}\left(k, X_{1}, X_{2}\right) \\
& U_{2}(\theta, y)=U_{2}{ }^{*}\left(k, X_{1}, X_{2}\right)
\end{aligned}
$$

Розв'язок по Нешу, згідно (1.7), визначається значенням $k$, яке максимізує добуток:

$$
\Phi(k)=\left[U_{1}{ }^{*}(k)-U_{1}(0)\right] \cdot\left[U_{2}{ }^{*}(k)-U_{2}(0)\right] \rightarrow \max
$$

\section{2. Постановка та розв'язок задачі.}

Розглянемо дві страхові компанії, страховика i перестраховика, 3 
ризиковими ситуаціями $\left(S_{i}, F_{i}(x)\right)$ та функціями корисності вигляду:

$$
u_{i}=1-e^{-a_{i} x},
$$

де $a_{i}>0$, які мають рівномірно розподілені випадкові величини сумарних страхових виплат $X_{i}$ з функцією розподілу:

$$
F_{i}(x)=\left\{\begin{array}{l}
0, x \leq 0 \\
\frac{x}{N_{i}}, 0<x \leq N_{i}, \\
1, x>N_{i}
\end{array}\right.
$$

де $N_{i}$ - максимальні збитки страхових компаній, $i=1,2$.

Знайдемо при таких вхідних даних оптимальний договір перестрахування між двома страховими компаніями або, що те саме, оптимальний перерозподіл загальних збитків $Z=X_{1}+X_{2}$.

Для характеристики початкових (до укладення договору) ризикових ситуацій ми згідно (1.2) отримаємо:

$$
\begin{gathered}
U_{1}(0)=\int_{0}^{N_{1}} u_{1}\left(S_{1}-x\right) d F_{1}(x)=\int_{0}^{N_{1}}\left(1-e^{-a_{1}\left(S_{1}-x\right)}\right) \cdot \frac{1}{N_{1}} d x \\
=\frac{1}{N_{1}} \cdot\left[N_{1}-\left.\frac{1-e^{-a_{1}\left(S_{1}-x\right)}}{a_{1}}\right|_{0} ^{N_{1}}\right]
\end{gathered}
$$

Тоді

$$
U_{1}(0)=1+\frac{e^{-a_{1} S_{1}}}{N_{1} a_{1}} \cdot\left[1-e^{a_{1} N_{1}}\right]
$$

Аналогічно для другої страхової компанії маємо:

$$
U_{2}(0)=1+\frac{e^{-a_{2} S_{2}}}{N_{2} a_{2}} \cdot\left[1-e^{a_{2} N_{2}}\right]
$$

Знайдемо вигляд величини збитків $h(k, Z)$ для страховика 3 одного 3 рівнянь системи (1.6):

або

$$
\frac{\partial}{\partial y} u_{1}\left(S_{1} \cdot(1-\theta)-y\right)=k \cdot \frac{\partial}{\partial y} u_{2}\left(S_{2}+S_{1} \cdot \theta-x_{1}-x_{2}+y\right)
$$

$$
a_{1} \cdot e^{-a_{1} \cdot\left(S_{1} \cdot(1-\theta)-y\right)}=k \cdot a_{2} \cdot e^{-a_{2} \cdot\left(S_{2}+S_{1} \cdot \theta-Z+y\right)}
$$

Після перетворень отримаємо:

$$
h(k, Z)=S_{1} \cdot \theta+y=\frac{\ln \left(\frac{k a_{2}}{a_{1}}\right)+a_{1} \cdot S_{1}-a_{2} \cdot\left(S_{2}-Z\right)}{a_{1}+a_{2}}
$$

Позначимо через

$$
\begin{gathered}
b(k)=\frac{\ln \left(\frac{k a_{2}}{a_{1}}\right)+a_{1} \cdot S_{1}-a_{2} \cdot S_{2}}{a_{1}+a_{2}}, \\
c=\frac{a_{2}}{a_{1}+a_{2}}
\end{gathered}
$$


Тоді

$$
h(k, Z)=b(k)+c \cdot Z
$$

або

$$
h(k, Z)=b(k)+c \cdot X_{1}+c \cdot X_{2}
$$

Тепер за допомогою формул (1.3), (1.4) i (1.8) знаходимо очікувані корисності ризикових ситуацій першої та другої компаній після укладення договору

$$
\begin{aligned}
U_{1}^{*}(k, Z)= & \int_{0}^{N_{2}} \int_{0}^{N_{1}} u_{1}\left(S_{1}-h(k, Z)\right) F_{1}^{\prime}\left(x_{1}\right) F_{2}^{\prime}\left(x_{2}\right) d x_{1} d x_{2} \\
& =\frac{1}{N_{1} N_{2}} \int_{0}^{N_{2}}\left[\int_{0}^{N_{2}}\left(1-e^{-a_{1}\left(s_{1}-h(k, Z)\right)}\right) d x_{1}\right] d x_{2}
\end{aligned}
$$

Користуючись (2.1с) :

$$
\begin{gathered}
U_{1}^{*}(k, Z)=\frac{1}{N_{1} N_{2}} \int_{0}^{N_{2}}\left[\int_{0}^{N_{2}}\left(1-e^{-a_{1}\left(s_{1}-b(k)-c \cdot x_{1}-c \cdot x_{2}\right)}\right) d x_{1}\right] d x_{2} \\
=1+\left.\frac{1-e^{N_{1} a_{1} c}}{N_{1} N_{2} a_{1} c} \cdot \frac{e^{-a_{1}\left(s_{1}-b(k)-c \cdot x_{2}\right)}}{a_{1} c}\right|_{0} ^{N_{2}}
\end{gathered}
$$

Маємо

$$
U_{1}^{*}(k, Z)=1-\frac{\left(e^{N_{1} a_{1} c}-1\right) \cdot\left(e^{N_{2} a_{1} c}-1\right)}{N_{1} N_{2}\left(a_{1} c\right)^{2}} \cdot e^{-a_{1}\left(s_{1}-b(k)\right)}
$$

Аналогічно обраховуємо $U_{2}^{*}(k, Z)$ :

$$
\begin{array}{r}
U_{2}^{*}(k, Z)=\int_{0} \int_{0} u_{2}\left(S_{2}+S_{1} \cdot \theta-x_{1}-x_{2}+y\right) F_{1}^{\prime}\left(x_{1}\right) F_{2}^{\prime}\left(x_{2}\right) d x_{1} d x_{2} \\
=\frac{1}{N_{1} N_{2}} \int_{0}^{N_{2}}\left[\int_{0}^{N_{2}}\left(1-e^{-a_{2}\left(s_{2}-x_{1}-x_{2}+h(k, Z)\right)}\right) d x_{1}\right] d x_{2}
\end{array}
$$

Поміняємо межі інтегрування місцями (це можна зробити внаслідок диференційованості підінтегральної функції по двох змінних $x_{1}$ i $x_{2}$ ). Спрощуючи, отримаємо:

$$
\begin{aligned}
U_{2}^{*}(k, Z)= & \frac{1}{N_{1}} \int_{0}^{N_{2}}\left[1+\frac{e^{-a_{2}\left(S_{2}+b(k)+(c-1) \cdot x_{1}\right)}}{N_{2} a_{2}(1-c)} \cdot\left(1-e^{N_{2}(1-c) \cdot a_{2}}\right)\right] d x_{1} \\
& =1+\left.\frac{1-e^{N_{2} a_{2} \cdot(1-c)}}{N_{1} N_{2} a_{2}(1-c)} \cdot \frac{e^{-a_{2}\left(S_{2}+b(k)+(c-1) \cdot x_{1}\right)}}{a_{2}(1-c)}\right|_{0} ^{N_{1}}
\end{aligned}
$$

В кінцевому результаті 


$$
U_{2}^{*}(k, Z)=1-\frac{\left(e^{N_{1} a_{2}(1-c)}-1\right) \cdot\left(e^{N_{2} a_{2}(1-c)}-1\right)}{N_{1} N_{2}\left(a_{2}(1-c)^{2}\right)} \cdot e^{-a_{2}\left(s_{2}+b(k)\right)}
$$

Отже, ми обрахували всі характеристики ризикових ситуацій двох страхових компаній до і після укладання договору по перестрахуванню і тому можемо безпосередньо переходити до знаходження сталої $k$, яка фігурує в функції $h(k, Z)$.

Спочатку знайдемо межі, в яких повинен знаходитись коефіцієнт $k$, щоби згідно нашої моделі страхові компанії покращили свої ризикові ситуації. Необхідною $є$ виконання умови (*).

Для страховика ми отримаємо, що

$$
U_{1}^{*}(k, Z)-U_{1}(0) \geq 0
$$

або що те саме

$$
\begin{gathered}
1-\frac{\left(e^{N_{1} a_{1} c}-1\right) \cdot\left(e^{N_{2} a_{1} c}-1\right)}{N_{1} N_{2}\left(a_{1} c\right)^{2}} \cdot e^{-a_{1}\left(s_{1}-b(k)\right)}-1-\frac{e^{-a_{1} S_{1}}}{N_{1} a_{1}} \cdot\left[1-e^{a_{1} N_{1}}\right] \geq 0 \\
\frac{N_{2} a_{1} c^{2}}{\left(e^{N_{1} a_{1} c}-1\right) \cdot\left(e^{N_{2} a_{1} c}-1\right)} \geq e^{-a_{1} \cdot b(k)}
\end{gathered}
$$

Зауважимо, що виходячи з рівняння (2.1a) :

$$
e^{a_{1} \cdot b(k)}=e^{A_{1} \ln \left(\frac{k a_{2}}{a_{1}}\right)+A_{2}}
$$

де $A_{1}$ i $A_{2}$ - константи, які залежать від $a_{1}, a_{2}, S_{1}, S_{2}$.

Важливим $є$ також те, що $A_{1} €$ більшим нуля. Для конкретної задачі завжди можна порахувати ці константи. Тоді

$$
k \leq \frac{a_{1}}{a_{2}}\left[e^{-A_{2}} \frac{N_{2} a_{1} c^{2} \cdot\left(e^{a_{1} N_{1}}-1\right)}{\left(e^{N_{1} a_{1} c}-1\right) \cdot\left(e^{N_{2} a_{1} c}-1\right)}\right]^{\frac{1}{A_{1}}} \equiv k_{\max }
$$

Ми знайшли верхню межу для $k$. Якщо $k^{*}$, яке максимізує рівняння (1.9), не буде його задовольняти, то перша компанія не буде укладати угоду.

Для другої страхової компанії аналогічно отримуємо умову на $k$, яка має задовольняти нерівність:

$$
U_{2}^{*}(k, Z)-U_{2}(0) \geq 0
$$

Аналогічно із знаходженням верхньої межі, в кінцевому результаті отримаємо:

$$
k \geq \frac{a_{1}}{a_{2}}\left[e^{-B_{2}} \frac{\left(e^{N_{1} a_{2}(1-c)}-1\right) \cdot\left(e^{N_{2} a_{2}(1-c)}-1\right)}{N_{1} a_{2}(1-c)^{2} \cdot\left(e^{N_{2} a_{2}}-1\right)}\right]^{\frac{1}{B_{1}}} \equiv k_{\text {min }}
$$

де $B_{1}$ і $B_{2}$ - константи, які залежать від $a_{1}, a_{2}, S_{1}, S_{2}$; константа $B_{1} \epsilon$ більшою за нуль.

Отже, ми знайшли умови на $k$, при яких виконується умова (*) для обох компаній. Очевидно, $k$, яке відповідає оптимальному договору, має належати проміжку $\left[k_{\min }, k_{\max }\right]$.

Умова $(* *)$ виконується за рахунок вибору пари $(\theta, y)$ або $h(k, Z)$ вигляду (2.1a). 
Таким чином маємо клас оптимальних договорів, з якого вибираємо за допомогою (1.9) шукану пару $\left(\theta^{*}, y^{*}\right)$, яка при цьому буде визначати оптимальний для обох компаній договір:

$$
\left[U_{1}^{*}(k, Z)-U_{1}(0)\right] \cdot\left[U_{2}^{*}(k, Z)-U_{2}(0)\right] \rightarrow \max
$$

Тепер потрібно знайти $k$ з проміжку $\left[k_{\min }, k_{\max }\right]$, яке максимізує функцію (1.9).

\section{Розпишемо}

$$
\begin{gathered}
\Phi(k)=\left[\frac{e^{-a_{1} S_{1}}}{N_{1} a_{1}} \cdot\left(e^{-a_{1} N_{1}}-1\right)-\frac{\left(e^{N_{1} a_{1} c}-1\right) \cdot\left(e^{N_{2} a_{1} c}-1\right)}{N_{1} N_{2}\left(a_{1} c\right)^{2}} \cdot e^{-a_{1}\left(s_{1}-b(k)\right)}\right] \\
\times\left[\frac{e^{-a_{2} S_{2}}}{N_{2} a_{2}} \cdot\left(e^{-a_{2} N_{2}}-1\right)-\frac{\left(e^{N_{1} a_{2}(1-c)}-1\right) \cdot\left(e^{N_{2} a_{2}(1-c)}-1\right)}{N_{1} N_{2}\left(a_{2}(1-c)\right)^{2}}\right. \\
\left.\cdot e^{-a_{2}\left(s_{2}-b(k)\right)}\right]
\end{gathered}
$$

Якщо розписати $c$ і $b(k)$ в $\Phi(k)$, тоді отримаємо наступне

$$
\begin{gathered}
\Phi(k)=\left[\frac{e^{a_{1} N_{1}}-1}{N_{1} a_{1} e^{a_{1} S_{1}}}-\frac{\left(e^{N_{1} \frac{a_{1} a_{2}}{a_{1}+a_{2}}}-1\right) \cdot\left(e^{N_{2} \frac{a_{1} a_{2}}{a_{1}+a_{2}}}-1\right)}{N_{1} N_{2}\left(\frac{a_{1} a_{2}}{a_{1}+a_{2}}\right)^{2}} \cdot e^{-\frac{a_{1} a_{2}}{a_{1}+a_{2}}\left(S_{1}+S_{2}\right)}\right. \\
\left.\cdot\left(\frac{k a_{2}}{a_{1}}\right)^{\frac{a_{1}}{a_{1}+a_{2}}}\right] \\
\quad \times\left[\frac{e^{a_{2} N_{2}}-1}{N_{2} a_{2} e^{a_{2} S_{2}}}-\frac{\left(e^{N_{1} \frac{a_{1} a_{2}}{a_{1}+a_{2}}}-1\right) \cdot\left(e^{N_{2} \frac{a_{1} a_{2}}{a_{1}+a_{2}}}-1\right)}{N_{1} N_{2}\left(\frac{a_{1} a_{2}}{a_{1}+a_{2}}\right)^{2}} \cdot e^{-\frac{a_{1} a_{2}}{a_{1}+a_{2}}\left(S_{1}+S_{2}\right)}\right. \\
\left.\cdot\left(\frac{k a_{2}}{a_{1}}\right)^{\frac{a_{2}}{a_{1}+a_{2}}}\right]
\end{gathered}
$$

Для зручності позначимо окремо доданки, які не залежать від $k$, i множники при $k$ наступним чином:

$$
\begin{gathered}
u_{1}=u\left(a_{1}, N_{1}, S_{1}\right) \equiv \frac{e^{-a_{1} S_{1}}}{N_{1} \cdot a_{1}}\left(e^{N_{1} a_{1}}-1\right) \\
u_{2}=u\left(a_{2}, N_{2}, S_{2}\right) \equiv \frac{e^{-a_{2} S_{2}}}{N_{2} \cdot a_{2}}\left(e^{N_{2} a_{2}}-1\right) \\
v \equiv \frac{\left(e^{N_{1} \frac{a_{1} a_{2}}{a_{1}+a_{2}}}-1\right)\left(e^{N_{2} \frac{a_{1} a_{2}}{a_{1}+a_{2}}}-1\right)}{N_{1} N_{2}\left(\frac{a_{1} a_{2}}{a_{1}+a_{2}}\right)^{2}} e^{-\frac{a_{1} a_{2}}{a_{1}+a_{2}}\left(S_{1}+S_{2}\right)}
\end{gathered}
$$

Тоді (2.6) перепишеться у вигляді: 


$$
\Phi(k)=\left[v\left(\frac{k a_{2}}{a_{1}}\right)^{\frac{a_{1}}{a_{1}+a_{2}}}-u_{1}\right] \times\left[v\left(\frac{k a_{2}}{a_{1}}\right)^{-\frac{a_{2}}{a_{1}+a_{2}}}-u_{2}\right] \rightarrow \max
$$

Виконавши операцію множення, отримаємо:

$$
\begin{gathered}
\Phi(k)=v^{2} \cdot k^{\frac{a_{1}-a_{2}}{a_{1}+a_{2}} \cdot\left(\frac{a_{1}}{a_{2}}\right)^{\frac{a_{2}-a_{1}}{a_{1}+a_{2}}}-u_{1} v k^{-\frac{a_{2}}{a_{1}+a_{2}}} \cdot\left(\frac{a_{1}}{a_{2}}\right)^{\frac{a_{2}}{a_{1}+a_{2}}}-u_{2} v k^{\frac{a_{1}}{a_{1}+a_{2}}}} \\
\cdot\left(\frac{a_{1}}{a_{2}}\right)^{\frac{-a_{1}}{a_{1}+a_{2}}}+u_{1} u_{2}
\end{gathered}
$$

Для знаходження екстремуму функції від одної змінної необхідно прирівняти першу похідну до нуля:

$$
\Phi^{\prime}(k)=0
$$

В результаті отримаємо:

$$
\begin{aligned}
\Phi^{\prime}(k)=v^{2} & \cdot \frac{a_{1}-a_{2}}{a_{1}+a_{2}} \cdot k^{\frac{a_{1}-a_{2}}{a_{1}+a_{2}}-1} \cdot\left(\frac{a_{1}}{a_{2}}\right)^{\frac{a_{2}-a_{1}}{a_{1}+a_{2}}}+u_{1} v \frac{a_{2}}{a_{1}+a_{2}} \cdot k^{-\frac{a_{2}}{a_{1}+a_{2}}-1} \\
& \cdot\left(\frac{a_{1}}{a_{2}}\right)^{\frac{a_{2}}{a_{1}+a_{2}}}-u_{2} v \frac{a_{1}}{a_{1}+a_{2}} k^{\frac{a_{1}}{a_{1}+a_{2}}-1} \cdot\left(\frac{a_{1}}{a_{2}}\right)^{\frac{-a_{1}}{a_{1}+a_{2}}}=0
\end{aligned}
$$

Після перетворень:

$$
v \cdot\left(a_{1}-a_{2}\right) k^{\frac{a_{1}}{a_{1}+a_{2}}} \cdot\left(\frac{a_{1}}{a_{2}}\right)^{\frac{a_{2}}{a_{1}+a_{2}}}+u_{2} \cdot a_{1} \cdot k-u_{1} \cdot a_{2} \cdot\left(\frac{a_{1}}{a_{2}}\right)=0
$$

або

$$
k+\frac{v}{u_{2}} \cdot\left(1-\frac{a_{2}}{a_{1}}\right) \cdot k^{\frac{a_{1}}{a_{1}+a_{2}}} \cdot\left(\frac{a_{1}}{a_{2}}\right)^{\frac{a_{2}}{a_{1}+a_{2}}}-\frac{u_{1}}{u_{2}}=0
$$

Таким чином бачимо, що в залежності від значень параметрів $a_{1}$ i $a_{2}$, рівняння (2.8) набуває вигляду:

$$
k-a \cdot k^{\vartheta}-b=0
$$

де $a, b$ i $\vartheta$ - константи.

В загальному випадку дане рівняння явно не розв'язується, але тут можна скористатися наближеними методами розв’язку рівнянь. Зауважимо, що оскільки $a_{2} \neq 0$, то :

$$
\vartheta=\frac{a_{1}}{a_{1}+a_{2}} \neq 1
$$

В даній ситуації можемо використовувати метод простих ітерацій:

$$
k_{0}=b, k_{i+1}=a \cdot k_{i}^{\vartheta}+b
$$

Послідовність $\left\{k_{i}\right\}_{i=0}^{+\infty}$ буде збігатися до $k^{*}$ - розв’язку (2.9). Покажемо це побудувавши графіки функцій $y_{1}=k$ i $y_{2}=a \cdot k^{\vartheta}+b$. Зрозуміло, що $a \geq 0$, $b>0,0<\vartheta<1$. Знайдемо розв'язок (2.9) графічно (рис.1). Значення $k$ в рівнянні (1.6) вибирали додатнім, оскільки рівняння (2.9) має сенс лише при додатних $k$. 


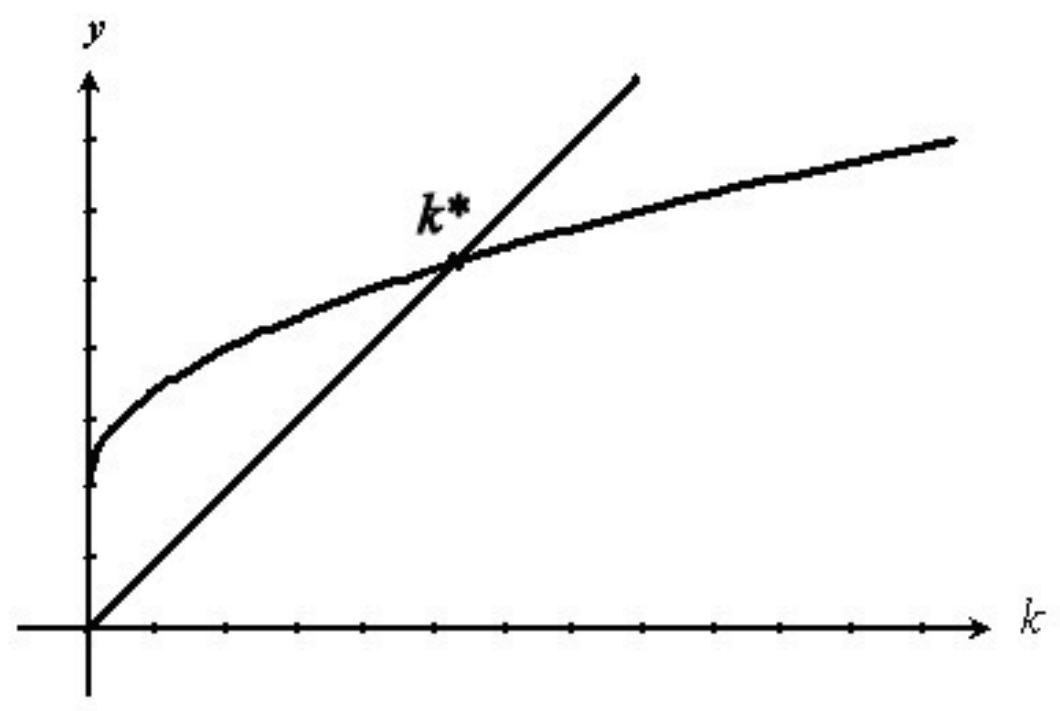

Рис.1. «Графіки функцій $y_{1}=k$ i $y_{2}=a \cdot k^{\vartheta}+b . »$

3 (рис.1) видно, що розв'язок (2.9) існує і він єдиний, позначимо його через $k^{*}$. Функція $y_{2}$ перетинає вісь ОY в точці $(0, b)$, вона неперервна і зростає на всьому проміжку від 0 до $+\infty$. Тому

$$
k^{*}>b
$$

\section{Висновки.}

Для поставленої задачі оптимальний розв 'язок за Нешем має наступний вигляд:

$$
h(k, Z)=S_{1} \cdot \theta+y=\frac{\ln \left(\frac{k a_{2}}{a_{1}}\right)+a_{1} \cdot S_{1}-a_{2} \cdot\left(S_{2}-Z\right)}{a_{1}+a_{2}}
$$

Запропонована модель не враховує можливість об`єднання компанійперестраховиків та виключає можливість банкрутства.

За допомогою отриманих результатів можна оцінити корисність перестрахування або використати їх для знаходження оптимального виду перестрахування, оптимального розподілу збитків між компаніями. Можливо вибрати оптимальний вид перестрахування, що часто використовують в страховому бізнесі, або знайти власний вид, оптимальний саме в даній ситуації.

Література:

1. Голубин А.Ю. Математические модели в теории страхования : построение и оптимизация / Голубин А.Ю. - Анкил, 2003 - ст. 17-21

2. Неш Дж. Бескоалиционные игры / Неш Дж. - Матричные игры, 1961. — ст. 205-211.

3. Borch K. The Economic Theory of Insurance - Edinburgh, 1964. - $132 \mathrm{p}$.

4. Pareto V. Manuel d'economie politique - Paris, 1947. — $264 \mathrm{p}$

5. Бауерс Н. Актуарная математика / Бауерс Н., Гербер Х., Джонс Д., Несбитт С., Хикман Дж. - Якус-К, 2001 - ст. 35-37

6. Гренандер У. Краткий курс вычислительной вероятности и статистики / Гренандер У., Фрайбергер В.- М., 1978. - 192 с. 
Abstract: It is considered relationships only between two insurance companies - insurer and reinsurer. It is found optimal contract of reinsurance that would satisfy these companies and it's living conditions were researched using criteria of expected utility of risk theory for insurance companies. We can valuate utility of reinsurance using obtained result and use them to define an optimal kind of insurance.

Key words: risk situation, Pareto optimality, Nash's solution.

\section{References:}

1. Golubin A.Yu. Mathematical models in insurance theory / Golubin A.Yu. Ankil, 2003 - p. 17-21

2. Nash J. non-cooperative games / Nash J. - Matrix Games, 1961. — p. $205-$ 211.

3. Borch K. The Economic Theory of Insurance — Edinburgh, 1964. - 132 p.

4. Pareto V. Manuel d'economie politique - Paris, 1947. - $264 \mathrm{p}$

5. Bauers N. Aktuarnaya matematika / Bauers N., Gerber H., Jones D., Nesbitt S., Hikman J. - Jakus-K, 2001 - p. 35-37

6. Hrenader U. Kratkiy kurs vychyslitelnoyi veroyatnosti I statisticki. / Hrenader U., Frayiberg V.- M., 1978. - 192 p.

Науковий керівник: канд.фіз.-мат.н., доц. Кінаш О.М.

Статя відправлена: 10.06.2018 г.

(c) Чорний P.O., Бевзюк O.В., Кінаш O.М. 